Visualizing Objects, Places, and Spaces: A Digital Project Handbook

\title{
Documentation for Temporal Projects
}

Beth Fischer, Hannah Jacobs, Kemba N'Namdi

Published on: Oct 14, 2019

DOI: $10.21428 / 51$ bee781.66e569f3

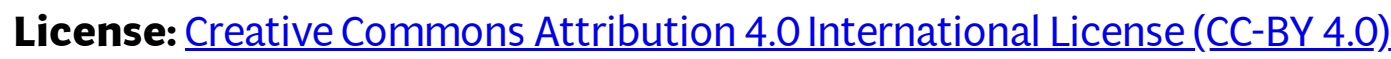




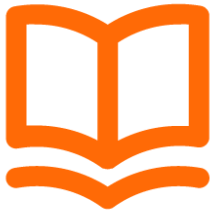

Most of the documentation for a timeline project will likely be included in the timeline itself, either in the code (for technical details) or in the content itself. As these projects tend to have a fairly quick turnaround, there is less likelihood that you will need to keep detailed project logs, though it is a good idea to save the materials from your initial project definition and wireframing process.

One special record you may need to create is a description of how you are editing or dividing temporal segments or assigning dates. When we take the typical unstructured, varied formats of events and historical records and try to put them into a structure like a timeline, we are often forced to make decisions about levels of detail and specificity for clarity and consistency. One example is the way museum exhibitions often describe objects by the century or partial century ("late 15th century," "2nd quarter 10th c." and so on). You might choose to keep this kind of dating or replace it with one of your own, so you would want to record that. You also might need to decide how to encode the many temporal events that occur over a length of time, like wars, people's lives, and even buildings.

The final documentation you may need is related to sources and copyright permissions. You should keep track of all your sources for attribution, but also so that you can return to them if you need to check a detail or change format: not just the creator of the original material, but also the source where you found it, like a website or a database. This is especially important for images and media. You should also record any details of permissions or copyright information that show that you are allowed to use media sources, even if the images are found through a web search or other public-facing source. A simple spreadsheet is usually the easiest way to keep track of all this, especially as it is common to use spreadsheets to enter material into a timeline anyway.

Continue Reading: $\underline{\text { Updates}}, \underline{\text { Maintenance, and Sustainability for Temporal }}$ Projects 